\title{
RESEARCH
}

Open Access

\section{The present and future burden of previously treated advanced non-small cell lung cancer (NSCLC) by histology and line of therapy in France, Germany, Italy, and Spain: model-based predictions}

\author{
David Campbell ${ }^{1 *}$ (D, Ken O'Day ${ }^{\prime}$, Nadine Hertel ${ }^{2}$, John R. Penrod ${ }^{3}$, Melinda Manley Daumont ${ }^{4}$ and Michael Lees ${ }^{4}$
}

\begin{abstract}
Background: The burden of advanced non-small cell lung cancer (NSCLC) is not well understood, and the number of patients likely to receive treatment in Europe has not been quantified. The aim of this study was to forecast the annual number of patients with squamous and non-squamous advanced NSCLC likely to receive second and third lines of therapy (LOT) from 2016 to 2020 in France, Germany, Italy, and Spain.

Methods: A patient count model (PCM) was developed in Microsoft Excel to estimate the number of patients with refractory advanced NSCLC eligible to receive systemic treatment. Using historical population-based cancer registry data, segmented linear regression ("Joinpoint") was used to forecast age- and sex-stratified lung cancer incidence rates in each country through 2020. Yearly incident case count totals by country were apportioned according to NSCLC histology and stage at diagnosis. Country-specific treatment rates came from a recent medical chart review study, and early- to advanced-stage disease progression rates were estimated over a 10-year interval. A probabilistic sensitivity analysis (PSA) was performed to estimate variability in the patient counts.

Results: The combined number of squamous and non-squamous advanced NSCLC patients estimated to receive second and third LOT, respectively, in 2016 were France = 11,600 and 3500; Germany = 15,100 and 4900; Italy $=13,500$ and 2500; Spain $=9400$ and 2100. The forecasted numbers of patients receiving second and third LOT, respectively, in 2020 were France $=13,900$ and 4200; Germany $=16,200$ and 5200; Italy = 15,100 and 2600; Spain $=11,000$ and 2500 .
\end{abstract}

Conclusions: Driven by growth in the incidence of NSCLC among women, the model forecasts an overall increase in the number of patients with advanced-stage squamous and non-squamous NSCLC likely to receive systemic treatment in the year 2020. The results highlight the significant burden of refractory advanced NSCLC and the need for more robust surveillance data to accurately quantify the burden of disease.

Keywords: Non-small cell lung cancer, Predictive model, Patient forecast, Patient number estimates, Treatment patterns, Line of therapy, Europe

\footnotetext{
* Correspondence: david.campbell@xcenda.com

${ }^{1}$ Xcenda LLC, Palm Harbor, Florida, USA

Full list of author information is available at the end of the article
}

(c) The Author(s). 2018 Open Access This article is distributed under the terms of the Creative Commons Attribution 4.0 International License (http://creativecommons.org/licenses/by/4.0/), which permits unrestricted use, distribution, and reproduction in any medium, provided you give appropriate credit to the original author(s) and the source, provide a link to the Creative Commons license, and indicate if changes were made. The Creative Commons Public Domain Dedication waiver (http://creativecommons.org/publicdomain/zero/1.0/) applies to the data made available in this article, unless otherwise stated. 


\section{Background}

Lung cancer is the leading cause of cancer-related death in Europe and throughout the world [1]. The World Health Organization (WHO) reports that each year there are more than 400,000 new cases of lung cancer in Europe and 1.8 million cases worldwide [2]. Lung cancer is commonly morphologically classified into small cell lung cancer (SCLC) and non-small cell lung cancer (NSCLC), with NSCLC accounting for approximately $85 \%$ of all lung cancer cases $[3,4]$. NSCLC can be further subclassified by tumor histology into squamous and nonsquamous disease, the latter including both adenocarcinoma and large cell carcinoma [5]. NSCLC clinical treatment pathways and outcomes vary according to the stage at diagnosis, morphology, tumor histology, mutation status, and performance status of the patient $[5,6]$. Patients with early-stage localized NSCLC may successfully undergo surgery. However, due to difficulties in diagnosing lung cancer, since symptoms may not appear until the disease has reached an advanced stage, the majority of patients are diagnosed at an advanced stage and are not candidates for surgery [5]. The prognosis for patients with advanced disease is poor, as the five-year survival rate for stage IV NSCLC is only $4 \%$ [5].

Due to the significant morbidity and mortality associated with NSCLC, it is important for health authorities to have a strong understanding of the disease epidemiology. However, published estimates of the projected number of incident cases of any type of cancer are limited. Furthermore, observed counts of prevalent patients in various stages of treatment within a defined geographic area have not been published and are not readily available in population-based cancer registries [1]. Dynamic patient count models (PCMs) using regional and national historical incidence rate data to project future incidence patterns by age, sex, and line of therapy (LOT) have been successful at addressing this data gap, with close concordance to GLOBOCAN registry findings [7]. The aim of this study was to forecast the annual number of patients with refractory squamous or non-squamous NSCLC likely to receive second and third LOT from 2016 to 2020 in France, Germany, Italy, and Spain in order to better quantify the burden of disease.

\section{Methods}

Model design

An Excel-based PCM was developed to forecast the number of previously treated advanced NSCLC patients in France, Germany, Italy, and Spain from 2016 to 2020 (Fig. 1). In addition to forecasting the overall annual NSCLC patient counts, the model was designed to allow stratification of these estimates across LOTs (second and third line) and histology (squamous and non-squamous).

To estimate the annual number of new advanced NSCLC cases in each country, age- and sex-stratified incidence rates were applied to United Nations (UN) world population data. Historical incidence rate data from the year 2000 through the current year of available

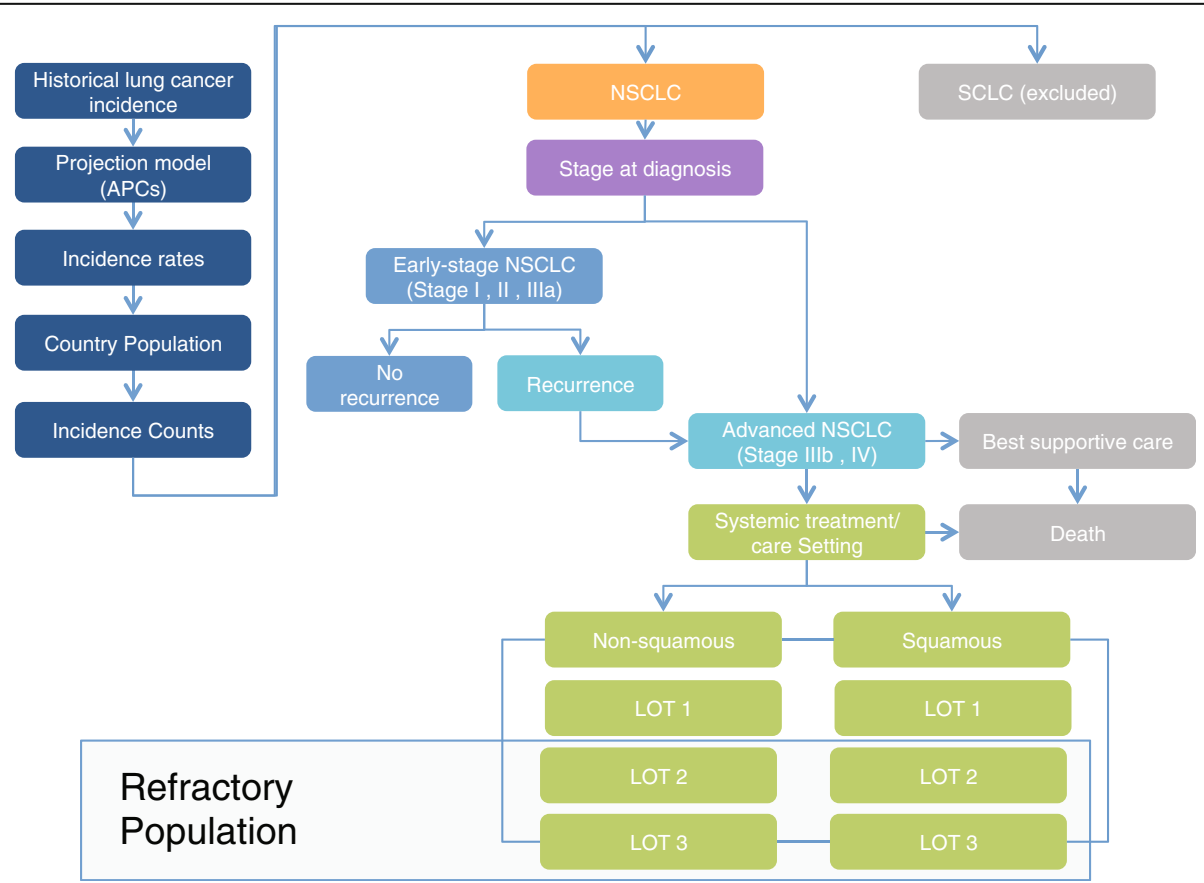

Fig. 1 Refractory NSCLC patient count model structure. Key: APC - annual percent change; LOT - line of therapy; NSCLC - non-small cell lung cancer; SCLC - small cell lung cancer 
data were used to construct a segmented linear regression model to determine 1) average annual incidence rate estimates; and 2) annual percent change (APC) estimates for the incidence rates [8]. The APC incidence estimates were then used to project future annual NSCLC incidence rates. Analyses to determine APC estimates were conducted using Joinpoint software [9].

Proportions of patients by histology and stage at diagnosis were then applied to the annual lung cancer incidence counts for each country. Patients classified as having SCLC were excluded from future counts in the model. NSCLC incidence counts were then stratified according to the proportion of patients with early- versus advanced-stage disease at diagnosis (early stage $=$ stages I, II, and IIIA; advanced stage = stages IIIB and IV). Data from published materials describing NSCLC progression from early to advanced stage over a 10-year time interval were modeled using a Weibull distribution. The value for the $\alpha$ scale parameter was calculated using five-year recurrence data, and the value for the $\beta$ shape parameter (i.e., accelerating or decelerating failure) was fit to the published survival curves using the least squares method. In this model, patients without recurrence were assumed to be cured of disease. Patients who receive non-systemic best supportive care (BSC) and do not receive systemic treatment from a medical oncologist were excluded from the total advanced NSCLC patient count. The proportion of those receiving systemic treatment by LOT and tumor histology (squamous or non-squamous) was applied to the annual case counts to calculate the annual country-specific patient counts by LOT. Estimated annual mortality was modeled in the same method as the recurrence calculation.

\section{Model parameterization}

Three types of data sources were used to parameterize the PCM. First, publicly available internet-based datasets, analysis tools, and reports of regional or national cancer registries were searched to obtain lung cancer incidence, prevalence, and mortality data (age- and gender-stratified); the proportion of patients by stage of NSCLC at diagnosis (stages I to IV); and morphology (NSCLC versus SCLC). Table 1 shows the data sources and types of data elements extracted from registry sources for each country.

The second data source for parameterizing the PCM included a comprehensive literature review on NSCLC epidemiology and treatment patterns. The comprehensive literature review used an approved set of database search terms, review of all retrieved titles/abstracts and relevant full-text papers, and quality assessment of the identified studies. The literature review of MEDLINE and EMBASE (2005-January 2015) identified 163 studies for full-text review, and 109 studies contained relevant data for extraction (see Additional file 1). As part of the quality control process for study screening, the literature review protocol required that a second independent reviewer spot-check $10 \%$ of the retained articles and $10 \%$ of the articles excluded during screening to ensure that the articles were being screened according to prespecified inclusion and exclusion criteria. Any disagreement over inclusion was resolved by discussion with a third, independent reviewer. Data were extracted by a single reviewer and were independently verified and validated by a second reviewer. When multiple data sources and parameter estimates were available, the most robust country-specific data source was selected as the default PCM parameter estimate. Quality was assessed by two independent reviewers by scoring studies across four parameters: 1) sample representativeness (selection bias); 2) study design; 3) quality of reporting (detection bias); and 4) attrition bias (see Additional file 2). If no country-specific data were available, aggregate estimates from other European countries were used to parameterize the PCM. Survival estimates for relapsed and refractory advanced NSCLC came from recent multinational randomized controlled studies [10, 11]. Finally, data from a retrospective chart review study of NSCLC treatment patterns in Europe were used to estimate the proportion of patients receiving second and third LOT by squamous or non-squamous tumor histology $[12,13]$.

APC incidence for each age and sex cohort was calculated, and the modeled estimates were used as the baseline incidence rate counts per year. Table 2 shows the incident APC estimates for the most recent Joinpoint segment.

Country-specific estimates for the morphology and histology of lung cancer are presented in Table 3. The

Table 1 Publicly available internet-based cancer registry data sources and data elements available for extraction by country

\begin{tabular}{llll}
\hline Country & Data sources & Data available & Incidence estimates data years $^{\text {a }}$ \\
\hline France & EUREG, InVS [29, 30] & Incidence and mortality & $2000-2009,2012$ \\
Germany & Robert Koch Institute [31] & Incidence and mortality & $2000-2012$ \\
Italy & AIRTUM/ITACAN [32, 33] & Incidence and mortality & $2000-2009$ \\
Spain & EUREG [29] & Incidence and mortality & $2000-2007$ \\
\hline
\end{tabular}

Key: InVS Institut de Veille Sanitaire, KRN Krajowy Reejestr Nowotworow

${ }^{a}$ Years refer to availability of incidence data; for modeling purposes, data were extracted only back through the year 2000 
Table 2 Annual percent change estimates by country, gender, and age for the last Joinpoint segment of the model

\begin{tabular}{|c|c|c|c|c|c|c|c|c|c|c|c|}
\hline \multicolumn{2}{|c|}{ Country and sex } & \multicolumn{10}{|c|}{ Age cohort } \\
\hline & & $40-44$ & $45-49$ & $50-54$ & $55-59$ & $60-64$ & $65-69$ & $70-74$ & $75-79$ & $80-84$ & $85+$ \\
\hline \multirow[t]{2}{*}{ France } & $M$ & $-4.8^{\mathrm{a}}$ & $-4.1^{a}$ & -0.8 & 0.8 & $1.4^{\mathrm{a}}$ & $1.5^{\mathrm{a}}$ & 0.6 & 0.6 & 0.7 & 4.1 \\
\hline & $\mathrm{F}$ & -1.8 & 1.2 & $8.2^{\mathrm{a}}$ & $8.6^{\mathrm{a}}$ & $8.5^{\mathrm{a}}$ & $7.9^{a}$ & $6.0^{\mathrm{a}}$ & $4.1^{\mathrm{a}}$ & 5.6 & $9.3^{\mathrm{a}}$ \\
\hline \multirow[t]{2}{*}{ Germany } & M & -6.4 & -5.1 & -6.8 & -1.3 & -0.4 & -0.6 & -2.7 & -4.8 & -0.6 & -0.1 \\
\hline & $\mathrm{F}$ & -2.8 & -2.7 & -1.9 & 2.6 & 6.4 & 6.1 & 2.1 & -2.2 & 1.9 & 3.2 \\
\hline \multirow[t]{2}{*}{ Italy } & M & $-7.3^{\mathrm{a}}$ & $-5.0^{\mathrm{a}}$ & $-4.6^{a}$ & $-3.5^{\mathrm{a}}$ & -0.9 & $-2.4^{a}$ & $-3.2^{\mathrm{a}}$ & $-1.4^{\mathrm{a}}$ & -3.8 & $2.2^{a}$ \\
\hline & $\mathrm{F}$ & -1.9 & $3.7^{\mathrm{a}}$ & $7.6^{\mathrm{a}}$ & $8.2^{\mathrm{a}}$ & $3.1^{\mathrm{a}}$ & $2.4^{a}$ & 1.2 & $1.9^{\mathrm{a}}$ & $3.8^{\mathrm{a}}$ & $6.4^{\mathrm{a}}$ \\
\hline \multirow[t]{2}{*}{ Spain } & M & $-4.5^{\mathrm{a}}$ & -2.3 & -2.0 & 1.9 & -0.1 & 0.8 & -0.5 & -0.2 & -1.5 & -7.6 \\
\hline & $\mathrm{F}$ & 1.9 & 9.5 & $14.9^{\mathrm{a}}$ & 4.5 & $10.2^{\mathrm{a}}$ & 4.3 & $7.2^{\mathrm{a}}$ & -1.5 & -1.0 & -1.8 \\
\hline
\end{tabular}

${ }^{a}$ Indicates that the annual percent change estimate is significant at $P<0.05$

Table 3 Model parameter estimates and data sources

\begin{tabular}{|c|c|c|c|c|c|c|}
\hline Parameter & & France & Germany & Italy & Spain & Model code color \\
\hline \multirow[t]{2}{*}{ Proportion non-small cell cases at diagnosis (\%) } & & 83.1 & 81.2 & 84.8 & 86.6 & \multirow[t]{5}{*}{ Orange } \\
\hline & Source & {$[34]$} & {$[35]$} & {$[32]$} & {$[36]$} & \\
\hline Squamous (\%) & & 38.3 & 35.9 & 32.2 & 40.5 & \\
\hline \multirow[t]{2}{*}{ Non-squamous (\%) } & & 61.7 & 64.1 & 67.8 & 59.5 & \\
\hline & Source & {$[12,13]$} & {$[12,13]$} & {$[32]$} & {$[12,13]$} & \\
\hline \multirow[t]{3}{*}{ Stage at diagnosis (\%) } & I & 7.5 & 13.7 & 10.0 & 7.4 & \multirow[t]{7}{*}{ Purple } \\
\hline & $\|$ & 7.9 & 8.3 & 5.9 & 6.2 & \\
\hline & III & 25.2 & 33.4 & 23.3 & 33.4 & \\
\hline \multirow[t]{4}{*}{ Proportion of stage III patients who are IIIb (\%) } & & 49.6 & 60.8 & 63.1 & 68.3 & \\
\hline & IV & 52.9 & 41.3 & 53.5 & 48.5 & \\
\hline & Unknown & 6.5 & 3.3 & 7.3 & 4.5 & \\
\hline & Source & {$[37]$} & & & & \\
\hline \multirow[t]{4}{*}{ Five-year rate of distant recurrence of the tumor from stage (\%) } & I & 25.8 & & & & \multirow[t]{8}{*}{ Blue } \\
\hline & $\|$ & 45.8 & & & & \\
\hline & IIla & 44.8 & & & & \\
\hline & Source & {$[38]$} & & & & \\
\hline \multirow[t]{4}{*}{ Median OS (months) } & Squamous NSCLC & 6.0 & & & & \\
\hline & Source & {$[10]$} & & & & \\
\hline & Non-squamous NSCLC & 9.4 & & & & \\
\hline & Source & {$[11]$} & & & & \\
\hline Proportion of advanced NSCLC patients referred to BSC (\%) & & $11.7 \%$ & & & & \multirow[t]{3}{*}{ Aqua blue } \\
\hline \multirow[t]{2}{*}{ Proportion eligible for systemic treatment (\%) } & & $88.3 \%$ & & & & \\
\hline & Source & {$[36]$} & & & & \\
\hline \multirow[t]{3}{*}{ Proportion of squamous patients receiving (\%) } & First LOT & 77.9 & 89.2 & 90.0 & 97.5 & \multirow[t]{7}{*}{ Green } \\
\hline & Second LOT & 28.6 & 37.8 & 42.2 & 39.2 & \\
\hline & Third LOT & 10.4 & 9.5 & 10.0 & 2.5 & \\
\hline \multirow[t]{4}{*}{ Proportion of non-squamous patients receiving (\%) } & First LOT & 89.5 & 93.8 & 92.3 & 99.1 & \\
\hline & Second LOT & 46.8 & 52.3 & 57.7 & 54.3 & \\
\hline & Third LOT & 12.9 & 18.5 & 8.7 & 16.4 & \\
\hline & Source & [13] & & & & \\
\hline
\end{tabular}


country-specific distributions of NSCLC stage at diagnosis were derived from a large observational, prospective cohort study on disease characteristics, treatment patterns, and outcomes related to treatment in select European countries (EPICLIN). Country-specific estimates of the second and third LOT treatment rate for squamous and non-squamous advanced NSCLC came from chart review studies of patients receiving care from a medical oncologist/pulmonologist. To validate model results, patient count forecasts were compared to published estimates of 2012 worldwide cancer incidence and mortality estimates by $\mathrm{WHO}$ and against published populationbased cancer reports $[1,14,15]$.

\section{NSCLC PCM sensitivity analysis}

A probabilistic sensitivity analysis (PSA) was conducted in which key model inputs, including APC, morphology, stage at diagnosis, tumor histology, five-year recurrence rate, proportion of patients receiving each LOT, and overall survival (OS) rate, were parameterized using appropriate distributions and standard errors calculated from the 95\% confidence intervals (CIs). Proportions were parameterized using beta distributions, APC incidence estimates were parameterized using normal distributions, time-to-event data were parameterized using Weibull distributions, and stage at diagnosis was parameterized using a Dirichlet distribution. A total of 1000 simulations were conducted, from which the mean, 95\% low CI, and 95\% high CI estimates were then calculated to obtain the probabilistic patient counts.

\section{Results}

The PCM forecasts an increase in the previously treated advanced NSCLC population for all countries between 2016 and 2020 (Table 4, Figs 2 and 3). The largest growth rate of second LOT-eligible patients was observed in France, where the model forecasts a compound annual growth rate of over $4 \%$.

\section{Discussion}

Lung cancer is the leading cause of cancer-related death in Europe and often remains undiagnosed until the tumor has reached an advanced stage, where patient survival is poor. New immune-oncology therapies approved for previously treated patients have significantly improved survival in clinical study and have the potential to improve the duration and quality of life for patients. However, data on the size of the treatment-refractory population in Europe that is eligible for these new therapies are limited. Reliable estimates of the population likely to receive treatment for refractory advanced NSCLC help improve the understanding of the potential clinical and economic impact of these new treatments.

In this study, we developed an Excel-based PCM to project country-level estimates of the number of patients receiving treatment for relapsed and refractory advanced NSCLC in France, Germany, Italy, and Spain over the five-year period from 2016 to 2020. For all countries, the model forecasts an overall increase in the number of patients with advanced-stage squamous and non-squamous NSCLC expected to receive second- and third-line treatment in the year 2020. The increase in patient numbers was driven primarily by growth in the incidence of NSCLC among women. Across the majority of countries and age groups, lung cancer incidence rates for females continued to increase, most notably in France. These data are in line with the current understanding of tobaccosmoking patterns and the epidemiology of lung cancer. Tobacco smoking is the leading risk factor for lung cancer and has been strongly associated with lung cancer, particularly with squamous SCLC and NSCLC [16]. In France, tobacco smoking has been attributed to $>80 \%$ of

Table 4 Deterministic and probabilistic model projections of the number of advanced NSCLC patients receiving second- and thirdline therapy in 2016 and in 2020 by country

\begin{tabular}{|c|c|c|c|c|c|c|c|c|c|}
\hline \multirow[t]{4}{*}{ Country } & \multirow{4}{*}{$\begin{array}{l}\text { Burden of } \\
\text { illness measure }\end{array}$} & \multicolumn{8}{|c|}{ Year of estimate } \\
\hline & & \multicolumn{4}{|l|}{2016} & \multicolumn{4}{|l|}{2020} \\
\hline & & \multirow{2}{*}{$\begin{array}{l}\text { Deterministic } \\
\text { Mean }\end{array}$} & \multicolumn{3}{|c|}{ Probabilistic } & \multirow{2}{*}{$\begin{array}{l}\text { Deterministic } \\
\text { Mean }\end{array}$} & \multicolumn{3}{|c|}{ Probabilistic } \\
\hline & & & Mean & Lower 95\% Cl & Upper 95\% Cl & & Mean & Lower 95\% Cl & Upper $95 \% \mathrm{Cl}$ \\
\hline \multirow[t]{2}{*}{ France } & Second LOT & 11,600 & 11,700 & 10,500 & 12,800 & 13,900 & 13,900 & 12,500 & 15,400 \\
\hline & Third LOT & 3500 & 3500 & 3200 & 3800 & 4200 & 4200 & 3800 & 4500 \\
\hline \multirow[t]{2}{*}{ Germany } & Second LOT & 15,100 & 15,200 & 13,600 & 16,700 & 16,200 & 16,200 & 14,600 & 17,900 \\
\hline & Third LOT & 4900 & 4900 & 4500 & 5400 & 5200 & 5300 & 4800 & 5700 \\
\hline \multirow[t]{2}{*}{ Italy } & Second LOT & 13,500 & 13,600 & 11,900 & 15,600 & 15,100 & 15,600 & 13,500 & 18,200 \\
\hline & Third LOT & 2500 & 2500 & 2200 & 2800 & 2600 & 2700 & 2400 & 3100 \\
\hline \multirow[t]{2}{*}{ Spain } & Second LOT & 9400 & 9600 & 8400 & 11,100 & 11,000 & 11,800 & 9600 & 14,700 \\
\hline & Third LOT & 2100 & 2200 & 1900 & 2400 & 2500 & 2600 & 2200 & 3300 \\
\hline
\end{tabular}


- 2016 - Advanced stage at diagnosis $₫ 2016$ - Advanced stage on progression

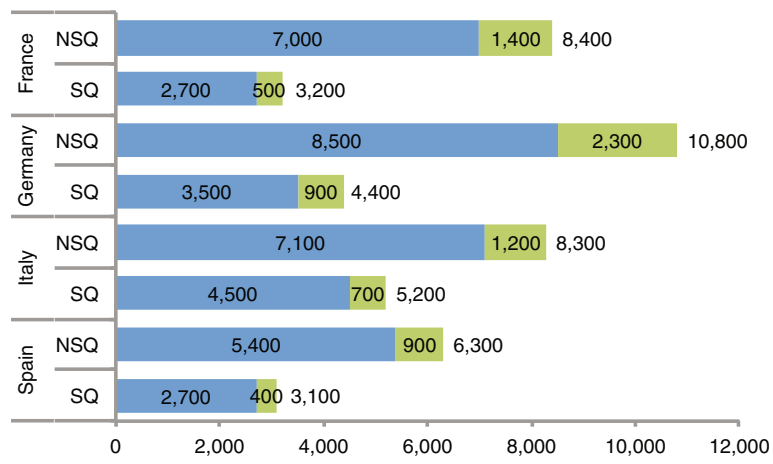

2020 - Advanced stage at diagnosis 2020 - Advanced stage on progression

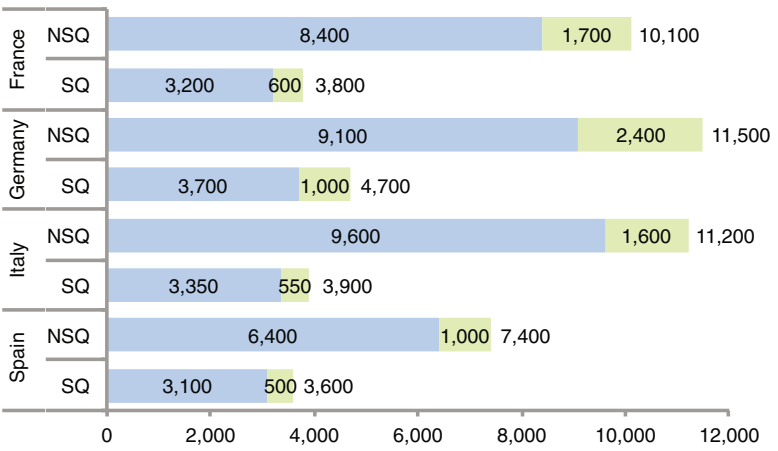

Fig. 2 Model projections of the number of advanced-stage NSCLC patients receiving second-line therapy in 2016 and 2020 by histology and country. Key: NSQ - non-squamous; SQ - squamous

lung cancer deaths [17]. Reflecting the earlier decline in smoking prevalence among men, lung cancer rates in men have either declined or plateaued, while rates of lung cancer in women continued to rise or, only recently, modestly decreased [18-20].

Lung cancer screening plays an important role in survival and disease trends for advanced NSCLC patients. The National Lung Screening Trial (NLST) found early screening of high-risk individuals with low-dose computed tomography (LDCT) reduces lung cancer-related mortality by $20 \%$ [21]. Following publication of these results, some professional organizations have recommended early screening in high-risk populations, but adoption of early screening efforts has been hindered by concerns related to radiation exposure, false positives, and cost [22]. Based on results of the NLST, ESMO clinical practice guidelines report LDCT reduces lung cancer-related mortality, but the guidelines cite many reasons to not recommend large-scale implementation, notably cost-effectiveness concerns [23]. Lung cancer screening rates were not included in the described PCM, but significant changes to screening rates could affect the number of patients eligible for treatment in the future and the validity of the model estimates.

There are limited published data on the current and future burden of relapsed and refractory advanced NSCLC in Europe; the patient count forecasts were validated against WHO data and published lung cancer reports. Forecasted results aligned with these published estimates and country trends in smoking and new lung cancer incidence. As an example, the model forecasts a compound annual growth rate of $4.5 \%$ in the number of patients receiving treatment in France, which matched the modeled growth rate published in a 2015 report by the French Institute for Public Health Surveillance (InVS) [14]. The InVS report projected 2015 lung cancer incidences of 45,222 , which is $0.5 \%$ lower than the 45,456 forecasted by the PCM. Using simple linear regressions of historical lung cancer incidence data by age and gender cohorts, combined with clinical treatment pattern data, has produced accurate patient forecasts.

The limitations of this study are mainly related to data used to parameterize the PCM and assumptions made in the PCM structure. The PCM assumes $11.7 \%$ of patients receive palliative care only and $88.3 \%$ are eligible to

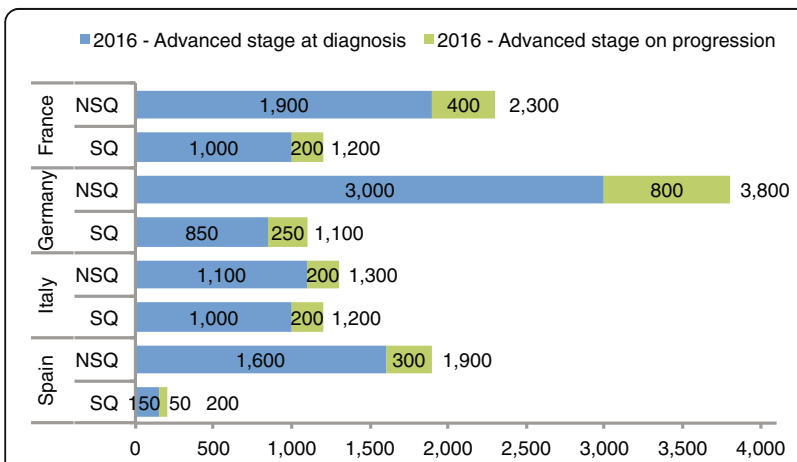

2020 - Advanced stage at diagnosis 2020 - Advanced stage on progression

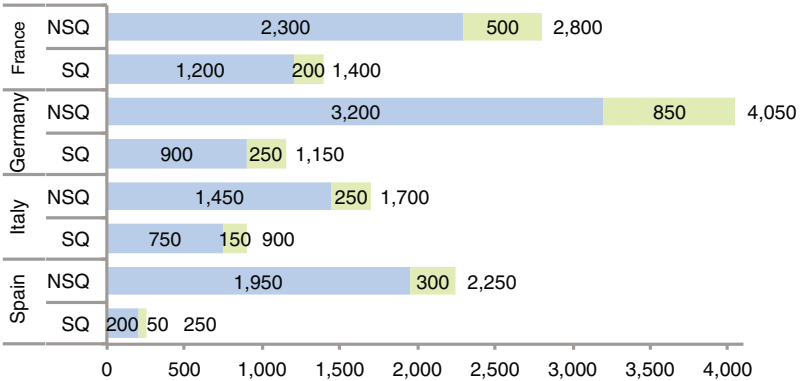

Fig. 3 Model projections of the number of advanced NSCLC patients receiving third-line therapy in 2016 and 2020 by histology and country. Key: NSQ - non-squamous; SQ - squamous 
receive systemic chemotherapy under the care of a medical oncologist. Due to the scarcity of published data on treatment rates of advanced NSCLC patients in France, Germany, Italy, and Spain, treatment rates utilized in the PCM were derived from a single retrospective chart review study of patients receiving first, second, and third LOT in the respective countries. However, published treatment rates reported for Canada, the United States, and the United Kingdom were generally lower (range: 26 to $58 \%$ ) than the rates used in the PCM, which may indicate that the PCM currently overestimates the treated population [24-28]. The PSA conducted as part of the modeling exercise provides a range of higher and lower patient number projections as the treatment rate is modified. Recurrence data were from population-based estimates reported in a recent study from Italy. While this study provides a robust estimate of the rates of recurrence, it is unknown to what degree different patient populations (in terms of country) or other factors, such as tumor histology, may influence this rate. Additionally, this study reviewed patient data from 2002 to 2005, which may differ from more current, real-world recurrence rates. Due to data limitations, we assumed that the median OS was the same across all countries, although different between squamous and non-squamous histology patients. Default OS estimates for all squamous and non-squamous advanced NSCLC patients were from the docetaxel arm of recent pivotal trials for nivolumab and may underestimate real-world survival rates as new treatments are adopted. However, the impact of varying this parameter did not significantly affect patient count estimates. Finally, we assumed that the APC estimate was a robust estimator of the trend in lung cancer incidence rates. All trend estimates, regardless of statistical significance, were applied to the last modeled estimated incidence rate for the data.

\section{Conclusions}

A modeling exercise was completed to estimate the future number of patients with advanced, refractory NSCLC eligible for systemic treatment in France, Germany, Italy, and Spain. The model forecasts an overall increase in the number of patients with advanced-stage squamous and non-squamous NSCLC likely to receive second- and third-line treatment in the year 2020 for all countries. Trends in advanced NSCLC treatment appear to be strongly gender-dependent. The increase in relapsed and refractory advanced NSCLC patients receiving treatment in 2020 is driven by growth in the incidence of lung cancer among women. Given the high mortality rates associated with advanced disease, the results of the model highlight the need for effective treatment options that can improve survival and for robust surveillance data to accurately quantify the burden of disease.

\section{Additional files}

Additional file 1: Comprehensive literature search results. Diagram summarizing results of the comprehensive literature search. (PDF $218 \mathrm{~kb}$ )

Additional file 2: Literature quality assessment criteria. Scoring criteria for the assessment of literature quality. (PDF $85 \mathrm{~kb}$ )

\section{Abbreviations \\ APC: Annual percent change; BSC: Best supportive care; Cl: Confidence interval; InVS: Institut de Veille Sanitaire; KRN: Krajowy Reejestr Nowotworow; LDCT: Low-dose computed tomography; LOT: Line of therapy; NLST: National Lung Screening Trial; NSCLC: Non-small cell lung cancer; NSQ: Non- squamous; OS: Overall survival; PCM: Patient count model; PSA: Probabilistic sensitivity analysis; SCLC: Small cell lung cancer; SQ: Squamous; UN: United Nations; WHO: World Health Organization}

\section{Acknowledgments}

The authors thank Dr. Jonathan Kish for his support at the initiation of this project and Mr. Paolo Di Rienzo for his critical review of the manuscript. The results of this study have been presented in the form of a poster at the International Society for Pharmacoeconomics and Outcomes Research 2016 meeting in Vienna, Austria, under the title "Results from a Model to Forecast the Current and Future Number of Patients Eligible for Treatment of Refractory Advanced Non-small Cell Lung Cancer (NSCLC) in France, Germany, Italy, and Spain." PCN288.

\section{Availability of data materials}

All data generated or analyzed during this study are included in this published article (and its additional information files).

\section{Funding}

This study was funded by Bristol-Myers Squibb Pharmaceuticals Ltd. The funder provided support in the form of salaries for authors $N H, J P, M M D$, and $\mathrm{ML}$, and the specific roles of these authors are articulated in the "author contributions" section. The funder had no role in the study design, data collection and analysis, decision to publish, or preparation of the manuscript.

\section{Authors' contributions}

All authors contributed to conceptualization: DC, KOD, NH, JP, MMD, and ML. DC and KOD completed data curation. DC, KOD, and NH developed study methodology, collected and synthesized data, and conducted the formal statistical analysis. All authors read, revised, edited, and approved the manuscript.

Ethics approval and consent to participate Not applicable.

Consent for publication

Not applicable.

Competing interests

The authors declare that they have no competing interests.

\section{Publisher's Note}

Springer Nature remains neutral with regard to jurisdictional claims in published maps and institutional affiliations.

\section{Author details}

${ }^{1}$ Xcenda LLC, Palm Harbor, Florida, USA. ${ }^{2}$ Worldwide Health Economics and Outcomes Research, Bristol-Myers Squibb Pharmaceuticals Ltd, Uxbridge, UK. ${ }^{3}$ Worldwide Health Economics and Outcomes Research, Bristol-Myers Squibb Pharmaceuticals Ltd, Princeton, NJ, USA. ${ }^{4}$ Worldwide Health Economics and Outcomes Research, Bristol-Myers Squibb Pharmaceuticals Ltd,

Rueil-Malmaison, France. 
Received: 12 September 2017 Accepted: 7 November 2018 Published online: 26 November 2018

\section{References}

1. Ferlay J, Soerjomataram I, Ervik M, Dikshit R, Eser S, Mathers C, et al. GLOBOCAN 2012 v1.0, cancer incidence and mortality worldwide: IARC Cancer Base no. 11. Lyon: International Agency for Research on Cancer; 2013. http://globocan.iarc.fr. Accessed 18 Nov 2015

2. GLOBOCAN. Fact sheets by population. 2012. http://gco.iarc.fr/today/factsheets-populations. Accessed 23 Nov 2015.

3. Cancer Research UK. Lung cancer incidence. 2014. http://www. cancerresearchuk.org/health-professional/cancer-statistics/statistics-bycancer-type/lung-cancer/incidence\#geog. Accessed 14 Feb 2016.

4. Molina JR, Yang P, Cassivi SD, Schild SE, Adjei AA. Non-small cell lung cancer: epidemiology, risk factors, treatment, and survivorship. Mayo Clin Proc Mayo Clin. 2008;83(5):584-94.

5. NCCN. Clinical practice guidelines in oncology. Non-small cell lung cancer. Version 3.2017. 2017. https://www.nccn.org/professionals/physician_gls/pdf/ nscl.pdf. Accessed 22 May 2017.

6. Novello S, Barlesi F, Califano R, Cufer T, Ekman S, Levra MG, et al. ESMO guidelines committee. Metastatic non-small-cell lung cancer: ESMO clinical practice guidelines for diagnosis, treatment and follow-up. Ann Oncol. 2016; 27(suppl 5):v1-v27.

7. Gueron B, Kish JK, O’Day K, Martel M, Daumont M. Patient count projections for advanced melanoma by line of therapy and other clinical characteristics in EU countries: results from the UK, Germany, France, Italy and Spain (EU-5). Amsterdam: International Society for Pharmacoeconomics and Outcomes Research (ISPOR) 17th Annual European Congress; 2014. Abstract ID: 39544

8. Population Division of the Department of Economic and Social Affairs of the United Nations Secretariat, World Population Prospects: The 2012 Theol Rev 2013. http://esa.un.org/unpd/wpp/. Accessed 27 Jun 2015.

9. Joinpoint Regression Program, Version 4.1.1. 2014; Statistical Research and Applications Branch, National Cancer Institute.

10. Brahmer J, Reckamp KL, Baas P, Crinò L, Eberhardt WE, Poddubskaya E, et al. Nivolumab versus docetaxel in advanced squamous-cell non-small-cell lung cancer. N Engl J Med. 2015;373(2):123-35.

11. Borghaei H, Paz-Ares L, Horn L, Spigel DR, Steins M, Ready NE, et al. Nivolumab versus docetaxel in advanced nonsquamous non-small-cell lung cancer. N Engl J Med. 2015;373(17):1627-39.

12. Solem C, Penrod JR, Lees M, Gueron B. Real-world treatment patterns among patients with advanced non-small cell lung cancer in Europe: evidence from a retrospective chart review in France, Germany, Italy and Spain. Presented at ESMO, 18th ECCO-40th ESMO European Cancer Congress. 2015

13. Campbell D, O'Day K, Penrod J, Kish J, Manley-Daumont M, Hertel, N. Results from a model to forecast the current and future number of patients eligible for treatment of refractory advanced non-small cell lung cancer (NSCLC) in France, Germanyr, Italy, and Spain. Presented at ISPOR European Congress 2016.

14. Institut National du Cancer. Les cancers en France en 2015 l'essentiel des faits et chiffres. https://www.e-cancer.fr/content/download/142167/1769928/ file/Les\%20cancers\%20en\%20france\%20-\%20Edition\%202015\%20\%20Faits\%20et\%20chiffres.pdf. Accessed 22 May 2016.

15. Leone N, Voirin N, Roche L, Binder-Foucard F, Woronoff AS, Delafosse P, et al. Projection of cancer incidence and mortality in metropolitan France in 2015. Technical Report. 2015. http://invs.santepubliquefrance.fr/Publicationset-outils/Rapports-et-syntheses/Maladies-chroniques-et-traumatismes/2015/ Projection-de--incidence-et-de-la-mortalite-par-cancer-en-Francemetropolitaine-en-2015. Accessed 22 May 2016.

16. Pesch B, Kendzia B, Gustavsson P, Jockel KH, Johnen G, Pohlabeln H, et al. Cigarette smoking and lung cancer-relative risk estimates for the major histological types from a pooled analysis of case-control studies. Int J Cancer. 2012;131(5):1210-9.

17. Ribassin-Majed L, Hill C. Trends in tobacco-attributable mortality in France. Eur J Pub Health. 2015;25(5):824-8.

18. Devesa SS, Bray F, Vizcaino AP, Parkin DM. International lung cancer trends by histologic type: male:female differences diminishing and adenocarcinoma rates rising. Int J Cancer. 2005;117(2):294-9.

19. Youlden DR, Cramb SM, Baade PD. The international epidemiology of lung cancer: geographical distribution and secular trends. J Thorac Oncol. 2008; 3(8):819-31.
20. Jemal A, Center MM, DeSantis C, Ward EM. Global patterns of cancer incidence and mortality rates and trends. Cancer Epidem Biomar. 2010;19(8): 1893-907.

21. Aberle DR, Adams AM, Berg CD, Black WC, Clapp JD, Fagerstorm RM, et al. Reduced lung-cancer mortality with low-dose computed tomographic screening. N Engl J Med. 2011;365:395-409.

22. Gulati S, Mulshine JL. Lung cancer screening guidelines: common ground and differences. Transl Lung Cancer Res. 2014;3(3):131-8.

23. Postmus PE, Kerr KM, Oudkerk M, Senan S, Waller DA, Vansteenkiste J, Escriu C, Peters S, ESMO Guidelines Committee. Early and locally advanced nonsmall-cell lung cancer (NSCLC): ESMO Clinical Practice Guidelines for diagnosis, treatment and follow-up. Ann Oncol. 2017;28(suppl_4):iv1-iv21.

24. Orsini LS, Korytowsky B, Petrilla A, Wisnivesky JP, Craver C, Salvati M, et al. Real-world use of systemic anti-cancer treatment by histology and line of therapy (LOT) in US Medicare patients with advanced non-small cell lung cancer (NSCLC). Presented at Chicago Multidisciplinary Symposium on Thoracic Oncology; 2014; Chicago, IL, USA.

25. Owonikoko TK, Ragin C, Chen Z, Kim S, Behera M, Brandes JC, et al. Realworld effectiveness of systemic agents approved for advanced non-small cell lung cancer: a SEER-Medicare analysis. Oncologist. 2013;18(5):600-10.

26. Noonan K, Tong KM, Laskin J, Melosky B, Sun S, Murray N, et al. Referral patterns in advanced non-small cell lung cancer: impact on delivery of treatment and survival in a contemporary population based cohort. Lung Cancer. 2014 Dec;86(3):344-9.

27. Sacher AG, Le LW, Lau A, Earle C, Leighl NB. Metastatic NSCLC: treatment patterns, outcomes, and costs of newer agents. J Clin Oncol. 2012;suppl; abstr 7606.

28. Royal College of Physicians. National Lung Cancer Audit annual report 2015 (for the audit period 2014). London: Royal College of Physicians; 2015.

29. Steliarova-Foucher E, O'Callaghan M, Ferlay J, Masuyer E, Forman D, Comber $\mathrm{H}$, Bray F: European Cancer Observatory: cancer incidence, mortality, prevalence and survival in Europe. Version 1.0. European Network of Cancer Registries, International Agency for Research on Cancer. 2012. https://ecis.jrc ec.europa.eu/. Accessed 6 June 2016.

30. Institut de Veille Sanitaire. Estimation nationale de l'incidence et de la mortalite par cancer en France entre 1980 et 2012. Etude a partir des registres des cancers du reseau Francim - Partie 1: tumeurs solides. 2013. http://invs.santepubliquefrance.fr/pmb/invs/(id)/PMB_11619. Accessed 12 Feb 2016.

31. German Centre for Cancer Registry Data. Robert Koch Institute. www. krebsdaten.de/database. Accessed 15 Mar 2016.

32. AIRTUM. Italian Association of Cancer Registries online tool. 38 registries pool, 2006-2009 data. 2014. http://itacan.ispo.toscana.it/English/itacan.htm. Accessed 07 June 2016.

33. ITACAN. About ITACAN. http://itacan.ispo.toscana.it/English/itacan.htm. Accessed 26 Jun 2016.

34. Locher C, Debieuvre D, Coëtmeur D, Goupil F, Molinier O, Collon T, et al. Major changes in lung cancer over the last ten years in France: the KBPCPHG studies. Lung Cancer. 2013;81(1):32-8.

35. Bristol-Myers Squibb GmbH \& Co. KGaA. Nivolumab dossier on the benefit assessment according to § 35a SGB V. 2015 Aug (36). 2015. https://www.gba.de/downloads/92-975-924/2015-08-12_Modul3B_Nivolumab.pdf. Accessed 12 Jun 2016

36. Sánchez de Cos Escuín J, Serra Mitjans M, Hernández Hernández J, Hernández Rodríguez H, Abal Arca J, Parente Lamelas I, et al. The Spanish Society of Pulmonology and Thoracic Surgery Lung Cancer Cooperative Group-II registry. A descriptive study. Arch Bronconeumol. 2013;49(11): 462-7.

37. Carrato $A$, Vergnenègre $A$, Thomas $M$, McBride K, Medina J, Cruciani G. Clinical management patterns and treatment outcomes in patients with non-small cell lung cancer (NSCLC) across Europe: EPICLIN-lung study. Curr Med Res Opin. 2014;30(3):447-61.

38. Consonni D, Pierobon M, Gail MH, Rubagotti M, Rotunno M, Goldstein A, et al. Lung cancer prognosis before and after recurrence in a populationbased setting. J Natl Cancer Inst. 2015;107(6):1-12. 